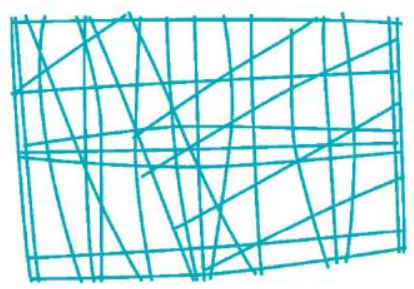

NEREUS

Núcleo de Economia Regional e Urbana

da Universidade de São Paulo

The University of São Paulo

Regional and Urban Economics Lab

COUNTERFACTUAL COMPARISONS OF INVESTMENT OPTIONS FOR WIND POWER AND AGRICULTURAL PRODUCTION IN THE UNITED STATES: LESSONS FROM NORTHERN OHIO

Alexandre Ribeiro Scarcioffolo

Fernanda Finotti Cordeiro Perobelli

Ariaster Baumgratz Chimeli

TD Nereus 01-2018

São Paulo

2018 


\title{
Counterfactual Comparisons of Investment Options for Wind Power and Agricultural Production in the United States: Lessons from Northern Ohio
}

\author{
Alexandre Ribeiro Scarcioffolo \\ West Virginia University \\ alexandre440@gmail.com \\ Fernanda Finotti Cordeiro Perobelli \\ Universidade Federal de Juiz de Fora \\ fernandafinotti.perobelli@ufjf.edu.br \\ Ariaster Baumgratz Chimeli \\ Universidade de São Paulo \\ chimeli@usp.br
}

\begin{abstract}
We analyze potential efficiency gains in wind power projects by comparing counterfactual investment decisions in two different scenarios under a real options framework. The first scenario is a standard wind power investment, where the investor rents the land from local farms. In the second scenario, the wind power investor buys the land and commercializes both electricity and crop production, thus shortening the revenue risk through the diversification. Both scenarios have a waiting option, with the wholesale prices leading the installation decision. We model the electricity price as a mean reverting process with jumps and with different jumping probabilities for the different seasons of the year. Corn prices follow a mean reverting process. The waiting flexibility was modeled as a bundle of European options. The results indicate that the waiting option is exercised in $100 \%$ of our simulations in both scenarios, suggesting the still important role of government policies to stimulate wind power. More importantly, in more than $90 \%$ of the simulations, the second scenario brought value to the investment. Furthermore, net present values are more sensitive to reductions in capital costs than electricity prices. These results can form the basis for more effective policies for the wind power sector.
\end{abstract}

Keywords: Wind Energy; Corn; Real Option Framework; Investment decision. 


\section{Introduction}

Several countries have been working to increase the share of renewable energy in their energy matrices in order to meet ever-increasing energy needs, and to promote a cleaner environment. Deployment of renewable energy resources has changed the landscape of power supply around the world (Gil, 2013) and wind energy is now one of the most promising and deployed renewable energy sources. Although much of the expansion in wind power in recent decades is due to its declining generation costs, most of this expansion has relied and still relies on government subsidies and incentives to make wind power production a competitive enterprise. This fact motivates the present study: here we explore potential efficiency gains in wind farm management that can guide both private agents in their investment decisions and policy makers in the design of incentive mechanisms. We do so by analyzing counterfactual investment decisions with a real options framework.

Our study builds on an institutional setting that is common in many parts of the United States. This includes subsidies for both agricultural production and renewable energy generation and distribution, renewable energy credits and renewable energy standards. To add realism to our work, we concentrate on a case study for corn and wind power production in Northern Ohio, but the approach we use offers a road map for other regions and agricultural products in the country.

The U.S ranked second in world wind energy generation capacity with $65.87 \mathrm{GW}$ in 2014 (NREL, 2014), following a steady growth over the years (Gil, 2013). To keep renewable energy's share increasing in their energy matrices, 28 U.S. states passed Renewable Portfolio Standards (RPS) mandates in recent years. The State of Ohio, for example, aims to increase the participation of renewable energy in its matrix by $12.5 \%$ by the year 2027 (DSIRE, 2014).

Our focus on choosing Ohio as a case study has several determinants. First, effective expansion of wind power is heavily dependent on costly transmission infrastructure (Hitaj, 2013). Ohio is a participant of the PJM jurisdiction, a regional transmission organization (RTO) that coordinates the wholesale electricity market in 13 states and the District of Columbia (PJM, 2014). PJM is the world's largest competitive wholesale 
organization in the electricity market, in great part due to the implementation of a number of efficiency-improving market and technical tools, such as a day-ahead and real-time locational marginal prices (LMP) and a congestion management system (FERC, 2002; Joskow, 2005). Second, wind power projects already exist in Ohio, especially in the Northern portion of the state. Furthermore investors, policy makers and scholars discuss the feasibility of both offshore and onshore wind power generation expansion in the state (see Wolmedorf and Chimeli, 2014, for example). Some of this expansion is proposed in marginal areas, which could increase the need for more efficient management. Finally, the co-existence of wind power generation with other economic activities within the same area in the state of Ohio, especially agricultural production, opens the possibility of efficient co-management of different investments.

Most onshore wind energy generators are installed on arable lands (Burton, 2001). The wind power investor usually rents the land in order to install turbines, access roads, and operate the maintenance building, in a way that crop production is minimally affected (Hau, 2013). Therefore, the relationship between farmers and wind energy producers can generate mutual gains, wherein the wind power producer takes advantage of wind resources in a given location and the farmer is compensated with rental payments. In an alternative context of sharing risk, it is also possible that the wind power investor purchases the land, rather than renting it. However, even if the price per square mile is low, the purchase of the land will not be economically feasible unless the investor has the intention to use the space for a second source of revenue (Hau, 2013), establishing partnerships with farmers.

In this study, we explore an avenue for efficiency improvements for wind power enterprises, where the wind power producer would operate in the wholesale market with the added flexibility of waiting for the best moment to invest. Here we assume that returns to wind power investments depend on electricity price levels in the spot market. In making this assumption, we do not attempt to analyze the feasibility of existing wind power projects, since many of these are dependent upon long-term contracts, which contain information that is private to the involved parties. Instead, we wish to build two comparable scenarios describing alternative investment opportunities. In the first scenario, the wind power producer rents the land from local farmers. In the second scenario, the wind power investor buys the land and commercializes both electricity and 
the crop production, sharing risks and expertise with farmers, thus shortening the revenue risk through the diversification.

We assume the main project uncertainty in the first scenario is the price of electricity. In contrast, with the inclusion of crop production in the second scenario, two main uncertainties emerge: electricity price and crop price uncertainties. Due to the high volatility of the electricity prices in the wholesale market as well as the presence of jumps, negative values and seasonal behavior, we model the day-ahead LMP as a meanreverting process with jumps. A distinctive feature of our model is the incorporation of different probabilities of occurrence of jumps in each season. The prevailing crop in Northern Ohio, where wind power production already takes place, is corn and in order to model the behavior of corn price over time, we assume it follows a mean-reverting process without jumps. We assume the decision to invest in a wind farm operating in the wholesale market will be directly dependent on the price of electricity in the first scenario, and on the prices of electricity and corn in the second scenario. We model the wait-and-see flexibility to invest as an European option and we solve for the model with a Monte Carlo simulation.

Our framework is symmetrical in the sense that a corn farmer could invest in wind power generation. However, agricultural producers in the U.S. typically invest in small wind farms due to high transactions costs stemming from their limited tax liabilities, need to form a partnership with a tax-motivated equity investor and a policy to support renewables based on non-refundable tax credits instead of grants (Bolinger and Wiser, 2006). In addition, agricultural farms may be located in areas where access to the power grid is prohibitively costly (Hitaj, 2013). For these reasons, we use a different starting point: given the actual incentive to invest in a larger wind farm (100MW), we investigate different investment opportunities for the wind power entrepreneur as well as different public policies to more efficiently promote wind power expansion. In section 4 , we further discuss different wind farm financial structures.

Our study produced some interesting insights. First, the waiting option is exercised in $100 \%$ of the simulations in both scenarios. This result suggests that investment in wind power generation still relies on public support in a number of cases. Even increasing the diversity of the investment, buying the land in order to operate in the crop market was 
not enough to make the investment feasible. However, this result should be interpreted with care, since our simulation is not capable of specifying wind power revenues accurately. More interestingly for the purposes of this paper, assuming a hypothetical and counterfactual wind power project that operates in a competitive electricity market and comparing both scenarios, we conclude the addition of the crop production in the investment brought value to the investment in more the $90 \%$ of all simulations. Second, our simulation results suggest that net present values (NPV) are more sensitive to proportional changes in capital costs (capital expenditures or CAPEX) than electricity prices. This might offer guidance to policy makers considering price-related policies such as feed-in tariffs as opposed to incentives to investment in research and development that lowers capital costs.

This paper is organized in six sections in addition to this introduction. Section 2 discusses the literature on option price methods applied to wind power projects and the modeling of electricity prices. In Section 3 we describe our modeling approach and section 4 describes different wind farm financial structures. Section 5 specifies the data and further assumptions we use in our simulation exercise. Section 6 discusses our results and section 7 concludes.

\section{Real Options and Wind Power}

Real option theory has been applied to various types of projects and sectors, and a number of studies and applications have recently focused on the renewable energy sector (Blyth et al, 2007; Fuss et al, 2008, Laurikka, 2006; Wickart \& Madlener, 2007; Yang et al, 2008). These studies usually concentrate on uncertainties stemming from electricity prices that dictate the feasibility of the project, government subsidies that make them more competitive in the energy market, the sales environment and the installation costs of different projects. We add to the existing real options literature applied to wind power in two ways: the construction of the uncertainty scenarios and the appropriate modelling of these uncertainties.

Abadie and Chamorro (2014) evaluated a wind power supplier in operation under different electricity sales environments in the U.K. The uncertainties that were present 
in their study were the future price of electricity in the deregulated market, wind power level, and the price of production certificates. Using both Monte Carlo simulation and trinomial trees, the authors assessed the project under different electricity sales environments. Their results suggest that an initial subsidy seems to have larger impact on the wind power project than a fixed premium per MWh produced. This result can be compared to our findings that wind power projects are more responsive to capital cost reductions than power price increases.

Méndez et al. (2009) evaluated the volatility of the investment in wind projects in Spain using sequential real options. The authors combined various uncertainties, such as cost of investment, production, and electricity price to decide whether the investment in the project should continue to the next stage or be abandoned, and the stages were successive and independent. They show that the project's development stage presents the major risk of the investment. This stage is therefore the most likely to trigger the abandonment option. Luna et al. (2003) evaluated the expansion option of an existing wind project in Colombia. The authors explored two types of uncertainty in their study: market and private. To characterize market uncertainty, they used the price in the spot market for electricity, which is correlated with GDP. As for private uncertainty, they focused on immaturity of the wind power sector. The authors used binomial trees to value the expansion option, and their results suggest that the value of the expansion option decreases with time as it is not exercised. Although both studies used real options framework, none considered combining a wind power project with other activities that might generate positive benefits for the wind project, such as combining agriculture and electricity production.

$\mathrm{Yu}$ et al. (2006) evaluated the switch option in wind projects. The options of wind projects were to sell electricity in the regulated market with fixed prices, in the spot market with varying rates, or even switching in both markets. They find that the yearly switchable tariff was the most indicated to reduce the operational risk of the project. Muñoz et al. (2009) evaluated the hold or abandonment investment options in wind projects using the electricity market prices and wind regimes as uncertainties. The authors used the trinomial tree to value the investor's decision in accordance with projections of various scenarios, generating different probabilities for exercising the deferring option or the abandonment option. However, even considering different 
switch options, they concentrate on the electricity market itself, not looking for different investment opportunities outside of the sector.

Dykes and Neufville (2008) evaluated investment in wind power generation using decision trees and Monte Carlo simulation with the option to expand the project or abandon it. The uncertainties Dykes and Neufville used in their work were the price of electricity and revenue from carbon credits. Their results show that if the wholesale electricity price rose by $5 \%$ yearly, the project would be feasible in the long run. Our work differs from these studies to the extent that we consider the possibility that the wind power producer buys the land and shares risk with the crop producer in order to maximize joint revenues from crop and power production.

Our real options analysis hinges on the treatment we give to electricity prices. The modeling of electricity prices has been studied by several scholars, ${ }^{1}$ and one commonly observed aspect of the electricity spot price is its mean-reverting process. ${ }^{2}$

A second feature that can be incorporated into the price of electricity is the presence of seasonal fluctuations stemming from variations in supply and demand in different seasons of the year and even hours of the day. In addition, electricity price series are characterized by small random movements around a trend, which can be represented by imbalances between supply and demand. As a stochastic feature, this can be represented by a white noise term. ${ }^{3}$

Finally, series for electricity prices often exhibit peaks, which are followed by a downward movement. The presence of peaks can be explained by the physical characteristics of electricity: electricity is an asset that cannot be stored after generation. The network has to balance demand and supply continuously, and demand and supply

\footnotetext{
${ }^{1}$ See for example Higgs \& Worthington, 2008; Huisman \& Mahieu, 2003; De Jong, 2006; Karakatsani \& Derek, 2008; Knittel and Roberts, 2001; Lucia \& Schawartz, 2002; Möst \& Keles, 2010; Pindyck, 1999; and Clewlow, Strickland, \& Kaminski, 2000.

2 Deng, 2000; Dias, 2004; Weron, Bierbrauer \& Trück, 2004; Geman \& Roncoroni, 2006; De Jong \& Huisman, 2002; and Bastian-Pinto, Brandão \& Hahn, 2009.

${ }^{3}$ The treatment of these wind price features appear in Weron, Bierbrauer \& Trück, 2004 and Geman \& Roncoroni, 2006.
} 
shocks cannot be mitigated in the very short run, thus causing the price of electricity to become quite volatile with several peaks over time. ${ }^{4}$

Electricity models must include these features to represent the characteristics of the market as closely as possible. Simple mean reversion movement (MRM) diffusion processes are insufficient to model the electricity price in the spot market (Kaminski, 1997). To model electricity spot prices, Clewlow et al. (2000), Hambly et al. (2009) and Higgs and Worthington (2008), added the possibility of jumps in the price series, thus better mimicking reality. We follow this literature to include the seasonal and peak components of electricity prices combined with the characteristics of corn prices in our models for present value calculations in different scenarios. Policy uncertainties were not included as risk factors.

\section{Model}

Assessment of the different investment options described above hinges on the distribution of key financial indicators, which depend on the stochastic nature of our price variables. Since the price of electricity and the agricultural crop are subject to quite different technical determinants, we use distinct models to simulate a time series for each variable.

\subsection{Model for scenario 1}

We assume that the relevant uncertainty in our first scenario, where the wind power producer leases the land, is the day-ahead LMP. We, therefore, base our approach on the Schwartz (1998) mean reverting model 1 diffusion process $d S=\eta(\alpha-\ln S) S d t+$ $\sigma S d z$, with $\alpha=\ln (\bar{S})$, implying $d S=\eta(\ln \overline{(S})-\ln S) S d t+\sigma S d z$, and where

$S$ is the stochastic variable;

$\bar{S}$ is the long-term equilibrium level of the stochastic variable;

$\eta$ is the reversion speed;

\footnotetext{
${ }^{4}$ See for example, De Jong, 2006; Clewlow, Strickland, \& Kaminski, 2000; Deng, 2000; Weron, Bierbrauer \& Trück, 2004; Geman \& Roncoroni, 2006; Bastian-Pinto, Brandão \& Hahn, 2009; Hambly, Howison \& Kluge, 2009; and Higgs \& Worthington 2008.
} 
$\sigma$ is the volatility of the process;

$d z$ is the standard Weiner process with a normal distribution $d z=\varepsilon \sqrt{d t}$;

$d t$ is the infinitesimal time increment of the process.

In order to simulate the stochastic variable in this mean reverting model and determine parameters of the process, Bastian-Pinto et al. (2009) proposed the following equation

$$
\begin{aligned}
& S_{t}=\exp \left\{\ln \left[S_{t-1}\right] e^{-\eta \Delta t}+\left[\ln (\bar{S})-\frac{\sigma^{2}}{2 \eta}\right]\left(1-e^{-\eta \Delta t}\right)\right. \\
& \left.+\sigma \sqrt{\frac{1-e^{-2 \eta \Delta t}}{2 \eta}} N(0,1)\right\}
\end{aligned}
$$

Consistent parameter estimation is done via ordinary least squares for the following model:

$$
\ln \left(S_{t} / S_{t-1}\right)=\underbrace{\left(1-e^{-\eta \Delta t}\right)\left(\ln \bar{S}-\sigma^{2} / 2 \eta\right)}_{a}+\underbrace{\left(e^{-\eta \Delta t}-1\right)}_{b-1} \ln S_{t-1}
$$

The speed of reversion, volatility and long-term mean are given by equations 3,4 and 5 (Bastian-Pinto et al., 2009), respectively

$$
\begin{gathered}
\eta=-\ln (b) / \Delta t \\
\sigma=\sigma_{\varepsilon} \sqrt{\frac{2 \ln b}{\left(b^{2}-1\right) \Delta t}} \\
\bar{S}=\exp \left[\left(a+\frac{\sigma_{\varepsilon}^{2}}{(1+b)}\right) /(1-b)\right]
\end{gathered}
$$

The Schwartz (1998) mean reverting model 1 is the basis for our simulation of electricity prices, but it does not model all the relevant aspects of this variable such as jumps, negative values, and seasonality. A common solution to tackle the first two drawbacks of the Schwartz model (jumps and negative values) is to add a jump 
diffusion process to the mean reversion process (Deng, 2000). To do so, we follow. Clewlow et al. (2000) and write

$$
d S=\underbrace{\eta(\ln \bar{S}-\ln S) S d t+S \sigma d z}_{a}+\underbrace{k S d q}_{b}
$$

Where $a$ is the Schwartz (Schwartz, 1998) mean reverting model 1, and $b$ is the jump process.

The proportional jump size is $k$, a random variable that is determined by the natural logarithm of the proportional jumps. The jumps are modeled in discrete time and their frequency is given by the random binary variable dq $\{0,1\}$ (Clewlow et al., 2000). Thus, the jump will occur only when dq is equal to 1 , and when dq is equal to zero the process becomes a simple mean reverting process.

Discretization of equation 6 yields:

$$
\begin{aligned}
S_{t}= & \exp \left\{\ln \left[S_{t-1}\right] e^{-\eta \Delta t}+\left[\ln (\bar{S})-\frac{\sigma^{2}}{2 \eta}\right]\left(1-e^{-\eta \Delta t}\right)+\sigma \sqrt{\frac{1-e^{-2 \eta \Delta t}}{2 \eta}} N(0,1)\right\} \\
& +(\bar{k}+\gamma N(0,1))\left(u_{i}\right. \\
& <\phi \Delta t)
\end{aligned}
$$

Where $\bar{k}$ and $\gamma$ are the mean jump size and the standard deviation of the jump, respectively. The parameter $\phi$ is the frequency of the jump and $u_{i}$ is uniformly distributed: $u_{i} \sim U(0,1)$. Therefore, the term $(\phi \Delta t)$ is the probability of jump occurrence. In our case, the price jumps in the electricity market reflect mainly the electricity market mismatches between demand and a low elasticity supply in a rigid short-term transmission system with limited inventories (Clewlow et al., 2000).

To insert this feature to the model, we consider the lagged value of the electricity price $\left(S_{t-1}\right)$ to calculate the next price level as a function of the mean reversion process only. That is, the jump diffusion process is removed from the calculation of the next price level. 


$$
\begin{aligned}
S_{t}=\exp \{ & \left.\ln \left[\operatorname{Smrp}_{t-1}\right] e^{-\eta \Delta t}+\left[\ln (\bar{S})-\frac{\sigma^{2}}{2 \eta}\right]\left(1-e^{-\eta \Delta t}\right)+\sigma \sqrt{\frac{1-e^{-2 \eta \Delta t}}{2 \eta}} N(0,1)\right\} \\
& +(\bar{k}+\gamma N(0,1))\left(u_{i}\right. \\
& <\phi \Delta t)
\end{aligned}
$$

Where $S m r p_{t-1}$ is the electricity lagged price from the mean reverting process.

Electricity consumption varies between seasons, with higher consumption taking place in the summer and winter months (Huisman \& Mahieu, 2003; Weron, Bierbrauer \& Trück, 2004; Geman \& Roncoroni, 2006). Thus, the size and the likelihood that a jump occurs is different for each season of the year, with summer and winter more likely presenting larger and more frequent jumps because of increased electricity consumption. We introduce this final feature of the electricity prices in our stochastic model with season-specific dummy variables and different probabilities of jump occurrence for different seasons:

$$
\begin{aligned}
& S_{t} \\
& =\exp \left\{\ln \left[\operatorname{Smrp}_{t-1}\right] e^{-\eta \Delta t}+\left[\ln (\bar{S})-\frac{\sigma^{2}}{2 \eta}\right]\left(1-e^{-\eta \Delta t}\right)+\sigma \sqrt{\frac{1-e^{-2 \eta \Delta t}}{2 \eta}} N(0,1)\right\} \\
& +\left\{\left[\theta_{s}\left(\bar{k}_{s}+\gamma_{s} N(0,1)\right)\left(u_{i}<\phi_{s} \Delta t\right)\right]+\left[\theta_{f}\left(\bar{k}_{f}+\gamma_{f} N(0,1)\right)\left(u_{i}<\phi_{f} \Delta t\right)\right]\right. \\
& +\left[\theta_{w}\left(\bar{k}_{w}+\gamma_{w} N(0,1)\right)\left(u_{i}<\phi_{w} \Delta t\right)\right] \\
& +\left[\theta _ { p } ( \overline { k } _ { p } + \gamma _ { s } N ( 0 , 1 ) ) \left(u_{i}\right.\right. \\
& \left.\left.\left.<\phi_{p} \Delta t\right)\right]\right\}
\end{aligned}
$$

Where $\theta_{s}, \theta_{f}, \theta_{w}$ and $\theta_{p}$ are the dummy variables for summer, fall, winter, and spring, respectively, and $\phi_{s} \Delta t, \phi_{f} \Delta t, \phi_{w} \Delta t$ and $\phi_{p} \Delta t$ are the probabilities of jump occurrence for the corresponding seasons. Also, $\bar{k}_{s}, \bar{k}_{f}, \bar{k}_{w}, \bar{k}_{p}, \gamma_{s}, \gamma_{f}, \gamma_{w}, \gamma_{p}, \phi_{s}, \phi_{f}, \phi_{w}$ and $\phi_{p}$ are the seasons-specific mean jump size, standard deviation of the jump, and the frequencies of the jumps. 


\subsection{Model for scenario 2}

For our second scenario, where the wind power producer generates electricity and shares risks with the crop producer (electricity and crop scenario), we assume two main sources of uncertainty in this case study: electricity price and corn price uncertainties. Corn prices are neither subject to jumps nor to the same volatility that affect electricity prices. As a typical a commodity, corn prices tend to follow a mean reversion process. Furthermore, since corn can be stored, we assume no seasonality in the price series. In our second scenario, we therefore model corn prices according to the Schwartz (1998) mean reverting model 1 diffusion process given by equations (1) - (5) along with equation (9) for electricity prices.

When we consider the joint ownership of the wind and agricultural farms, we do not specify how the different parts of the enterprise will be managed and what the internal contract structure will be. Instead, we simply assume risk sharing between the farmer and the wind power producer. We do so, because our main interest is on the overall efficiency of the project and we therefore simply account for the overall risk associated with each investment.

\section{U.S. wind farm ownership structure}

The wind farm ownership structure in the second scenario is based on the willingness of the wind power investor to diversify investment, possibly increasing economic gains through the agricultural market. However, it is important to clarify that there are other common structure ownership alternatives for wind farm projects, such as farmers investing in their own turbines - the so-called "farmer-owned wind project".

Farmer-owned wind projects can be a sole proprietorship or in conjunction with other farmers and partners, but in all cases it requires an up-front investment cost as well construction, maintenance and operation cost, increasing the risk of their business (Bolinger and Wiser, 2006). Farmers can benefit from wind power by selling the generated electricity to the grid, providing extra income that would hedge them from big swings in commodity prices or use the additional electricity to power their own farms, decreasing operation cost. However, these projects face a number of challenges in order 
to take advantage of state and federal incentives, which could be seen as an obstruction for future investment in this sector. The criteria for eligibility for tax-based incentives require that the farm-owned wind project presents enough tax liability, sell electricity to a third party and maintain a taxable ownership structure (Bolinger and Wiser, 2006). Additionally, because most farmers do not generate enough tax liability to fulfil the taxbased requirement, farm-owned wind projects usually need outsourced investors. To overcome financial and regulatory issues and to be eligible for a full array of federal and state incentives, different farm-owned wind project ownership structures must be designed.

Bolinger and Wiser (2006) describe four innovative farmer-owned wind ownership structures: (1) multiple local investors, (2) Minnesota-style "flip", (3) Wisconsin-style "flip", and (4) on-site projects. The multiple local investor model is organized as a limited liability company (LLC) in which one or more farmers develop a farmer-owned project that is financed by the local farming community through purchasing shares of the project. The remaining debt can be obtained from local banks or grants. The power generated is sold to a local utility through a long-term power purchase agreement in which the shareholders split the income and tax benefits proportionally to their initial level of investment. One of the main roadblocks of this structure is that equity shares are considered securities under federal and state law, hence they must be registered, increasing the total cost of the project.

The Minnesota-style "flip" structure is based on organizing a LLC with a single farmer/landowner who partners with a tax-motivated company eligible to benefit from all or most of the federal production tax credits. The initial equity share is usually divided unevenly; in this case, the local farmer can contribute as little as $1 \%$ to the LLC, while the company contributes the remaining amount, up to $99 \%$ of the LLC. During the first 10 years of the wind farm project, the cash flow and tax benefits are divided proportionally based on their investment levels. After the $10^{\text {th }}$ year (or possibly later if necessary), the ownership structure "flips" to a $99 \%$ local farmer and $1 \%$ company partner. The corporate partner has the option to hold the $1 \%$ of the project or sell it to the local farmer. Therefore, after the "flip," the local farmer owns a debt-free wind farm, receiving at least $99 \%$ of the cash flow until the end of the project's life. 
On the other hand, the Wisconsin-style "flip" structure is based on an LLC of multiple local farmers providing debt instead of equity in which local farmers pool enough capital by selling shares to cover a percentage (Bolinger and Wiser (2006) consider $20 \%$ ) of the project cost. Then they loan this money to a tax-motivated company that also contributes to the debt on some level. The remaining cost is obtained by the company partner from a financial institution. Hence, the company owns $100 \%$ of the project for the first 10 years, taking advantages of all or most of the federal production taxes credits and the cash flow from the project while concurrently making payments on the loans from the financial institution and the interest (not principal) for the loans acquired from the multiple local farmers. In year 11, the company drops out of the project, keeping the principal from the original loan from the farmers as a buyout. Therefore, the ownership "flips" and the multiple local farmers own $100 \%$ of the project as well the cash flow for the remaining period of the project. As for the multiple local investor model, this structure might face high costs to register the securities.

Finally, the on-site projects are organized not to sell electricity to the local utility but rather to provide power to the farm. The farmer is responsible for financing and connecting the turbines to the grid. Thus the power generated by the turbines is typically used in the farm activities. However, the on-site projects cannot take advantage of the federal credits, and the farmer is also subject to fees from the local utility. Thus, the four models presented so far were designed to overcome some of the roadblocks for investing in farm-owned wind projects. The success of these projects depends on state regulations as well as on finding a buyer for the generated electricity such as in the case of the first three structures. There might be other types of farm-owned wind farm structures that may be eligible for the full array of federal and state incentives.

Farm-owned wind projects are smaller in comparison with projects from wind development companies mainly because of their high initial capital cost and the need to meet tax liability eligibility requirements to receive tax-based incentives. For instance, in Iowa, the state with the highest wind capacity, $97 \%$ of the wind farms belong to wind development companies. ${ }^{5}$ Therefore, in order to evaluate the installation of a $100 \mathrm{MW}$ utility-scale wind farm, we decided to analyze the investment decision through the lens

\footnotetext{
${ }^{5}$ See Slate

http://www.slate.com/articles/technology/future_tense/2017/08/why_farmers_in_iowa_hope_wind_energy_will_blow over.html, accessed on November 6, 2017.
} 
of wind development companies. We do so, because investment in wind power by typical agricultural farmers at this level would be cost prohibitive.

Large corporations such as Amazon, Google, IKEA and others recently started investing in the renewable power sector. For instance, Amazon recently inaugurated its $208 \mathrm{MW}$ utility-scale wind farm that can produce enough energy for 61,000 homes annually in North Carolina. ${ }^{6}$ Thus, the possibility of companies investing in a different business niche such as wind power is real, and they command large enough resources to invest in joint wind power-agricultural farms if efficiency gains might result. These potential gains in a small but growing wind power market motivate our analysis.

\section{Data}

In this study, we consider the decision to invest in a hypothetical utility-scale wind power project with a capacity of $100 \mathrm{MW}$ and 50 turbines in the ATSI-PJM region. In the first scenario, the wind power investor rents the land and makes fixed payments to farmers in order to install the turbines for the project. The wind farm only leases a specific part of the farm, one in which there is no agreement on sharecropping between the wind farm and the farm. In the second scenario, the investor buys the land in order to produce for both the wind power and the agricultural markets, working in partnership with farmers.

To add realism to our study, we use market information on prices and costs that are publicly available. For example, we use spot market electricity prices in our simulation of cash flows for our wind power farm. However, many if not most prices that are paid for wind electricity are established in long-term contracts that are private to the buyers and sellers. We therefore do not attempt to calibrate our data to existing wind power projects, but instead simulate the impact of different investment options on their cash flows based on available information.

To conduct our exercise, we need to account for all sources of revenues for wind power projects. Besides selling electricity to the wholesale market, wind power producers can

\footnotetext{
${ }^{6}$ See DOE https://energy.gov/eere/articles/why-corporations-are-buying-us-wind-power, accessed on November 10 , 2017.
} 
usually increase their revenues by selling Renewable Energy Certificates (RECs). The price of a REC in the state of Ohio in 2014 was around US\$ 11 per MW/h (Hernan, 2014). In addition, PJM's participants can tap into the PJM's capacity market or the Reliability Pricing Model (RPM). The RPM consists of a series of auctions for the delivery of power in the future. These auctions provide price signals that encourage the retention and/or development of new resources in the region and provide greater reliability for the network. The price of the last Base Residual Auction (BRA) was US\$ 120 per MW - day (PJM, 2014). We assume constant prices for REC and BRA.

We suppose the wind power project is eligible for the Modified Accelerated Cost Recovery System (MACRS). The MACRS is a federal program of accelerated depreciation for projects of power generation from renewable sources (DSIRE, 2014). We also suppose that the project is eligible for the Qualified Energy Property Tax Exemption for Projects over $250 \mathrm{~kW}$. Considering that the wind power plant hires at least $75 \%$ of its employees from the State of Ohio, the property tax rate is US\$ 6,000 per MW capacity (DSIRE, 2014).

According to EPA (2013), the capital expenditures (CAPEX) for wind power projects in Northern Ohio with the above features, including the cost to connect to the grid, is US\$ 227,960,561 Table 1 contains the main parameters, variables and assumptions used for the valuation of the wind power project in our first scenario.

Following the financial specification from Table 1, we calculate the systematic risk ("beta" representing the asset's risk level that cannot be diversified) and the weighted average cost of capital (WACC) for the wind energy power project. These are 1.68 and $9.78 \%$, respectively.

Wind power projects usually take three years to be completed. However, the investment is not divided into three equal parts. The first year target is to build $20 \%$ of the project, whereas $35 \%$ is allocated to the second year, and the remaining $45 \%$ is built in the last year (Hau, 2013). Table 2 shows the structure of the free cash flow to the firm in the first scenario. 
The second scenario has the same financial features as the first, except for the incorporation of the cost of the farmland. In this scenario, we suppose the wind power project is located in a corn-producing farm in Northern Ohio as discussed in the introduction and the wind power producer buys the farmland and produces both electricity and corn. Corn is the locally prevailing crop and occupies more than 3.5 million acres in the region (USDA, 2014). A few wind farms already exist in Northern Ohio and we use one of them, the Blue Creek project (Iberdrola Renewables, 2014), as our benchmark. Our purpose is not to reproduce their financial structure, since much information is private to the firm, but simply to use one actual farm to provide us with benchmark information such as used area and production capacity. We therefore base our simulations on a farm with approximately 17,067 acres, where 50 acres are devoted to wind power generation infrastructure and the remainder is allocated to corn production. The average price of an acre in Ohio in 2012 was US\$ 4,460 (USDA, 2014), and an acre produced about 166 bushels of corn, on average (Foreman, 2014).

Foreman (2014) segregates corn farm costs into two types: (i) operating costs and (ii) property costs. Operating costs vary directly with the quantity of corn produced. In our second scenario, we suppose that electricity is directly supplied to the production of corn and we therefore abate this cost from our estimates of operating costs. Property costs refer to capital consumed in the production process, such as capital costs and the substitution of machines and equipment, along with insurance costs. In this scenario, the land-leasing cost for the wind power producer is also eliminated. According to Hau (2013), this cost represents $6 \%$ of the firm's annual revenue. Finally, we suppose that corn production benefits from government transfers. Foreman (2014) reports that $93 \%$ of farms with more than 1,000 acres received US\$ 49,408 per farm on average in government payments in 2010. Table 3 contains the summary of the data we use in our simulations for scenario 2 .

With the financial specification from Table 3, we calculate the beta and the WACC for the corn farm project. These are 0.679 and $7.54 \%$, respectively. In order to calculate the beta and the WACC from the second scenario, we consider the betas and WACCs based on the project returns so as to balance the risks and capital structures of the wind power project and the corn farm. The beta and WACC from the second scenario are 1.09 and $8.49 \%$, respectively. Table 4 shows the free cash flow of the second scenario. 


\section{Results}

\section{Model parameters}

Before we report estimated model parameters, we first note that a jump, as in the case of electricity prices, can only be observed as part of a time series that includes a mean reverting behavior. The definition of a jump must appeal to the intuitive idea that jumps represent "very large" price spikes (Clewlow et al., 2000). The precise definition is necessarily arbitrary and, in this paper, we define three standard deviations from the historical average (US\$ 73.03) as our threshold value for a jump.

Parameter estimation takes place in a two-step approach. First, we filter the jumps out of the price series and replace those with the threshold value before the estimation of the mean reverting parameters. For the second step, we separate the jumps for the different seasons in order to estimate the relevant frequency, the average size, and the standard deviation of the jump for each season.

The historical series for the hourly day-ahead LMP from ATSI_PJM from 06/01/2012 to 05/31/2013 period was obtained from the PJM's database (PJM, 2014). We then adjusted the series for inflation with the electric sector PPI for 2012. Model parameters were estimated for the inflation-adjusted LMP series, and our search for jumps identified 115 prices, occurring mainly during the summer season. We followed Bastian-Pinto et al. (2009) in our estimation process and the results appear in Table 5 and Table 6. The comparison between the simulated and the historical series of electricity price appear in Figure 1.

We performed a mean difference test, and did not reject the null hypothesis that the means of simulated and real series were equal. Additionally, in order to assess the power of the model, we compared the distribution of the real and simulated data. According to the Akaike Information Criterion (AIC), the log logistics distribution produces the best fit for both distributions.

As for corn, we estimated the model parameters based on the historical series of the 
monthly corn price ranging from January 1947 to May 2013 from the National Agricultural Statistics Service - USDA (USDA, 2014). We adjusted the series for inflation with the corn PPI for 2012. We then estimated the model parameters for the inflation-adjusted corn price series according to Bastian-Pinto et al. (2009). The results appear in Table 7. The comparison between the simulated corn grain price and the historical series of corn grain price is shown in Figure 2. Assessment of the power of the model followed the same testing procedure as in the case of electricity prices.

\section{Simulation}

Next, we generated electricity and corn prices to estimate a distribution of present values in the two scenarios described above. To generate electricity prices, we separately ran four sets of 4,000 simulations, one for each season of the year. Each simulation relied on the day-ahead LMP recorded on an hourly basis to produce the price distribution with the best fit for each season. We also ran 4,000 simulations for corn prices based on the distribution of actual monthly prices. Table 8 summarizes the simulated electricity and corn prices. We generate price levels for a twenty-year horizon starting in January 2015.

Figure 3 plots the estimated distributions of present values for the first scenario, where wind power producers lease the land (PV1), and for the second scenario, where wind power producers own the land and produce both corn and electricity (PV2). For comparison purposes, we also estimated the present values for a standard corn farm with the same features of scenario two (PV3). There is a clear rightward shift in the distribution of present values when we consider the option of jointly operating both businesses - electricity and corn production. Likewise, a rightward shift also occurs when we consider the distributions of net present values, that is, present values minus capital expenditures (CAPEX). The results appear on Figure 4.

Figure 4 plots the distributions over a negative range of net present values for our simulations. That is, present values are not large enough to cover the estimated capital expenditures. This might seem surprising at first, but we notice two important points. First, we do not to attempt to calibrate our results to match actual net present values, since doing so would require information that is not readily available. For example, we 
do not have private information on electricity prices from long-term contracts between wind power producers and consumers. Instead, we use spot market electricity prices to simulate a benchmark scenario where wind electricity would compete with power from other sources. Second, wind power production is still heavily subsidized around the world through feed in tariffs, renewable portfolio standards, tax breaks and other incentives that we might have underestimated in our exercise. This is an indication that wind power is still not fully competitive in different parts of the world and many producers would prefer not to operate in the absence of existing incentives.

A more promising view of our simulation consists of an exploration of alternative investment options relative to the status quo. For example, the median net present value for scenario 1 corresponds to the $35^{\text {th }}$ percentile in scenario 2 . Furthermore, our results allow us to conduct sensitivity analysis that might inform investors and policy makers on the variables that might have a larger impact on net present values as they change. For example, if net present values are relatively sensitive to price changes, then a policy on feed in tariffs might be more effective, whereas relative sensitivity to capital expenditures calls for policies that directly incentivize the development of lower cost technologies. We turn to this exercise next.

\section{Sensitivity Analysis}

Our sensitivity analysis concentrates on variations in electricity price and CAPEX, and we do not attempt to incorporate policy uncertainty in this analysis. The focus on these two variables relies on their importance for several renewable energy polices and also for the calculation of the net present value. For example, feed-in tariffs are common in several countries and guarantee minimum electricity prices for renewable energy power producers. Other policies target grants to research and development for reducing renewable energy capital costs.

Figure 5 shows the response of net present values to changes in electricity prices in both scenarios. The first noticeable result is that net present values in scenario 2, which combines production of wind power and corn, dominate net present values in scenario 1 for every price level change from its baseline. Second, not even a $100 \%$ increase in electricity price relative to its baseline is sufficient to bring net present values to a 
positive level in either scenario. Furthermore, a $100 \%$ increase in electricity price is unlikely in the near future, given declining coal, natural gas and oil prices in recent years as well as declining electricity demand since 2009 (Wiser, 2015a).

In contrast to variations in electricity prices, changes in CAPEX have a more pronounced impact on net present values. Figure 6 indicates that for higher capital costs, relative to the CAPEX baseline, the option to produce wind power only dominates the option to produce both corn and electricity. Clearly, NPVs are negative with such a change and wind power projects would only make sense with subsidies or mandates such as renewable portfolio standards. On the other hand, as CAPEX declines, joint ownership of the wind power enterprise and the corn farm produces higher NPVs than the common practice of producing wind power only. In addition, NPV becomes positive for an approximately 50\% reduction in CAPEX in scenario 2, as opposed to a much larger $80 \%$ reduction in CAPEX required in scenario 1 . To put these figures in perspective, the International Energy Agency (EIA), The European Wind Energy Association (EWEA) and The Global Wind Energy Council (GWEC) estimate a CAPEX reduction of $18 \%, 29 \%$ and $18 \%$ by 2030 , respectively. Gielen (2012) estimate that CAPEX could fall by as much as $43 \%$ by 2040 due to learning effects, increased research and development, wind turbine capacity increases, expansion of the supply chain, greater dedicated installation capacity and increased competition.

Several commentators recommend the use of policies to stimulate wind power production and that may involve the use of public funds in some level. This recommendation rests on the argument that renewable energy generates positive externalities that are not accounted for in unregulated markets. If public policies are indeed implemented, our sensitivity analysis results suggest that policies designed to promote the reduction in capital costs are more likely to produce better results than those policies meant to guarantee higher prices.

\section{Conclusion}

We consider two investment scenarios involving wind power generation: a wind power project alone and a wind power project combined with crop production, corn being our case study. Whereas the first scenario captures the typical existing wind power projects, 
we investigate whether the latter option outperforms the former. Our analysis also contributes to the efficient design of public policies for renewable energy as it offers insights into the relative effectiveness of policy instruments to stimulate wind power in the US. In our modelling strategy, we consider electricity prices as the main source of uncertainties affecting the investment in the first scenario and electricity and corn prices in the second. We model electricity prices as mean reversion process with jumps and different distributions of jumps in each season, and we assume that corn prices follow a mean reversion process.

From our simulation results, the waiting option is exercised in $100 \%$ of the simulations in both scenarios. However, the second scenario's present values, when wind power production is combined with corn production, were greater than the first scenario's present values $93.4 \%$ of the time. The levelized cost of energy (LCOE) for the second scenario is smaller than that for the first, requiring less government subsidies to stimulate wind power production. In addition, we estimate that, given a baseline situation where the investment is not feasible in either scenario, not even a $100 \%$ increase in electricity prices would be enough to make present values positive. In contrast, a reduction of $80 \%$ in CAPEX in the first scenario and only around $50 \%$ in the second scenario would be enough to make the wind power generation feasible. A $100 \%$ increase in electricity prices is unlikely, given recent trends, whereas a 50\% reduction in CAPEX affecting wind power generation is much closer to existing projections for the industry. Therefore, if public subsidies for wind power generation are implemented, our results suggest that they are most effective if they target capital cost reductions in joint wind-crop farms, and least effective and efficient if they target electricity prices (such as feed-in tariffs) in projects producing wind power alone.

We analyze the investment decision through the lens of a utility-scale wind power investor (100MW project) that may decide to operate in partnership with a crop producer instead of taking the perspective of a farmer that chooses to invest in a wind power project (typically much smaller than a 100MW wind farm). We do so, because, as discussed elsewhere (Bolinger and Wiser, 2006), the existing institutional setting in the US makes it very costly for typical farmers to invest in wind power production. In principle, we could investigate the decision by agricultural farmers to invest in wind power within a Real Options framework, but this would require different premises and 
we leave such an analysis as an open question for future research.

\section{Reference}

Abadie, L.M. and Chamorro, J.M., 2014. Valuation of wind energy projects: A real options approach. Energies, 7(5), pp.3218-3255.

Bastian-Pinto, C., Brandão, L. and Hahn, W.J., 2009. Flexibility as a source of value in the production of alternative fuels: The ethanol case. Energy Economics, 31(3), pp.411422.

Blyth, W., Bradley, R., Bunn, D., Clarke, C., Wilson, T. and Yang, M., 2007. Investment risks under uncertain climate change policy. Energy policy, 35(11), pp.57665773.

Bolinger, Mark, and Ryan Wiser. 2006. A comparative analysis of business structures suitable for farmer-owned wind power projects in the United States. Energy Policy 34(14), pp.1750-1761.

Burton, T., Sharpe, D., Jenkins, N. and Bossanyi, E., 2001. Wind energy handbook. John Wiley \& Sons. 642 p.

Clewlow, L., Strickland, C. and Kaminski, V., 2000. Jumping the gaps. Energy and Power Risk Management Magazine, pp.26-27.

Clewlow, L., Strickland, C. and Kaminski, V., 2001a. Extending mean-reversion jump diffusion. Energy Power Risk Management, Risk Waters Group, 5.

De Jong, C., 2006. The nature of power spikes: A regime-switch approach. Studies in Nonlinear Dynamics \& Econometrics, 10(3).

De Jong, C. and Huisman, R., 2002. Option formulas for mean-reverting power prices with spikes. Energy Global Research Paper

Deng, S., 2000. Stochastic models of energy commodity prices and their applications: Mean-reversion with jumps and spikes. Berkeley: University of California Energy Institute. Retrieved from

$<$ http://citeseerx.ist.psu.edu/viewdoc/download?doi=10.1.1.16.1116\&rep=rep1\&type=p df $>$. [accessed 10.09.14].

Dias, M.A.G., 2004. Valuation of exploration and production assets: an overview of real options models. Journal of Petroleum Science and Engineering, 44(1), pp.93-114.

DSIRE, Database on state incentives for renewables and efficiency, Solar Center, North Carolina State University. Retrieved from <http://www.dsireusa.org/>. [accessed 05.28.14]

Dykes, K. and Neufville, R.D., 2008. Real options for a wind farm in Wapakoneta, Ohio: incorporating uncertainty into economic feasibility studies for community wind. In World Wind Energy Conference, Kingston, Ontario, Canada, June. Retrieved from 
<http://ardent.mit.edu/real_options/Real_opts_papers/Dykes_\%20WWEC\%202008_Fin al_Oct08.pdf >. [accessed 11.08.14].

EPA, 2013. Power Sector Modeling Platform v.5.13. U.S Environmental Protection Agency. Retrieved from <http://www.epa.gov/airmarkets/documents/ipm/Documentation.pdf >. >. [accessed 08.20.14].

FERC, Federal Energy Regulatory Commission, 2002. Working paper on standardized transmission service and wholesale electric market design. March, 15, p.1.

Foreman, Linda, 2014. Characteristics and Production Costs of U.S. Corn Farms, Including Organic, 2010. EIB-128, U.S. Department of Agriculture, Economic Research Service. Retrieved from <http://www.ers.usda.gov/media/1673846/eib128.pdf>. [accessed 09.27.14].

Fuss, S., Szolgayova, J., Obersteiner, M. and Gusti, M., 2008. Investment under market and climate policy uncertainty. Applied Energy, 85(8), pp.708-721.

Geman, H. and Roncoroni, A., 2006. Understanding the fine structure of electricity prices. The Journal of Business, 79(3), pp.1225-1261.

Gielen, D., 2012. Renewable energy technologies: cost analysis series-wind power. In IRENA working paper. International Renewable Energy Agency (IRENA).

Gil, H. and Lin, J., 2013. Wind power and electricity prices at the PJM market. Power Systems, IEEE Transactions on, 28(4), pp.3945-3953.

Hambly, B., Howison, S. and Kluge, T., 2009. Modelling spikes and pricing swing options in electricity markets. Quantitative Finance, 9(8), pp.937-949.

Hau, E., 2013. Wind Turbines: Fundamentals, Technologies, Application, Economics. Springer. 897p.

Hernan, Arancha. Marex Spectron RECs prices. [email]. [Received email 11.21.14].

Higgs, H. and Worthington, A., 2008. Stochastic price modeling of high volatility, mean-reverting, spike-prone commodities: The Australian wholesale spot electricity market. Energy Economics, 30(6), pp.3172-3185.

Hitaj, C., 2013. Wind power development in the United States. Journal of Environmental Economics and Management, 65(3), pp.394-410.

Huisman, R. and Mahieu, R., 2003. Regime jumps in electricity prices. Energy economics, 25(5), pp.425-434.

Iberdrola renewables, 2013. Fact Sheets of Blue Creek. Retrieved from $<$ http://iberdrolarenewables.us.files.s3.amazonaws.com/pdf/blue-creek-fact-sheet.pdf.>. [accessed 06.11.14]. 
Joskow, P.L., 2005. Markets for power in the United States: An interim assessment. AEI-Brookings Joint Center Working Paper, (05-20).

Kaminski, V., 1997. The challenge of pricing and risk managing electricity derivatives. The US Power Market, 3, pp.149-71.

Karakatsani, N.V. and Bunn, D.W., 2008. Forecasting electricity prices: The impact of fundamentals and time-varying coefficients. International Journal of Forecasting, 24(4), pp.764-785.

Knittel, C.R. and Roberts, M.R., 2001. An empirical examination of deregulated electricity prices. POWER Working Paper No. PWP-087. Retrieved from $<\mathrm{http}: / /$ ssrn.com/abstract=294382 > [accessed 06.11.14].

Laurikka, H., 2006. Option value of gasification technology within an emissions trading scheme. Energy Policy, 34(18), pp.3916-3928.

Lucia, J.J. and Schwartz, E.S., 2002. Electricity prices and power derivatives: Evidence from the nordic power exchange. Review of derivatives research, 5(1), pp.5-50.

Luna, A., Assuad, C. and Dyner, I., 2003, July. 'Wind Energy in Colombia: An Approach from the Real Options. In Universidad Nacional de Colombia. Proceedings of the 21st International Conference of the System Dynamics Society in New York City. Retrieved from <http://www.systemdynamics.org/conferences/2003/proceed/PAPERS/356.pdf>. [accessed: 06.23.2014].

Méndez, M., Goyanes, A. and Lamothe, P., 2009. Real options valuation of a wind farm. Universia Business Review. Retrieved from <http://realoptions.org/papers2009/46.pdf>. [accessed 03.13.2014]

Möst, D. and Keles, D., 2010. A survey of stochastic modelling approaches for liberalised electricity markets. European Journal of Operational Research, 207(2), pp.543-556.

Munoz, J.I., Contreras, J., Caamano, J. and Correia, P.F., 2009, June. Risk assessment of wind power generation project investments based on real options. In PowerTech, 2009 IEEE Bucharest (pp. 1-8). IEEE. Retrieved from $<\mathrm{http} / / /$ ieeexplore.ieee.org/xpl/articleDetails.jsp?arnumber=5281848>. [accessed 11.08.14].

NREL. National Renewable energy Laboratory. Retrieved from <http://www.nrel.gov/>. [accessed 04.20.2014]

PJM, PJM. Retrieved from <http://www.pjm.com/>. [accessed 06.27.17]

Schwartz, E., 1998. Valuing long-term commodity assets. Journal of Energy Finance \& Development, 3(2), pp.85-99. 
USDA, 2010. Usual planting and harvesting dates. US Department of Agriculture, Statistical Reporting Service 2007. Retrieved from

<http://usda.mannlib.cornell.edu/usda/current/planting/planting-10-29-2010.pdf >. [accessed 09.22.14].

, 2014. Unite States Department of Agriculture. Retrieved from

<http://www.usda.gov/>. [accessed 08.07.14].

,2014a. Census of Agriculture of 2012, Summary and State Data. U.S.

Department of Agriculture, National Agricultural Statistics Service 2012. Retrieved from

<http://www.agcensus.usda.gov/Publications/2012/Full_Report/Volume_1,_Chapter_1_ US/usv1.pdf>. [accessed 09.20.14].

2014b. Land Values, 2014 Summary. US. Department of Agriculture, National

Agricultural Statistics Service. Retrieved from

<http://usda.mannlib.cornell.edu/usda/nass/AgriLandVa//2010s/2014/AgriLandVa-08-

01-2014.pdf>. [accessed 09.05.14].

Weron, R., Bierbrauer, M. and Trück, S., 2004. Modeling electricity prices: jump diffusion and regime switching. Physica A: Statistical Mechanics and its Applications, 336(1), pp.39-48.

Wickart, M. and Madlener, R., 2007. Optimal technology choice and investment timing: a stochastic model of industrial cogeneration vs. heat-only production. Energy Economics, 29(4), pp.934-952.

Wiser, Ryan, 2014. 2012 wind technologies market report. Retrieved from <http://escholarship.org/uc/item/3d3661ds>. [accessed 01.21.14].

Wiser, Ryan, 2015a. 2014 wind technologies market report. Retrieved from <http://energy.gov/sites/prod/files/2015/08/f25/2014-Wind-Technologies-MarketReport-8.7.pdf $>$. [accessed 11.10.15].

Womeldorf, C.A. and Chimeli, A.B., 2014. A computational fluid dynamics approach to wind prospecting: Lessons from the US Appalachian region. Energy Policy, 73, pp.645653.

Yang, M., Blyth, W., Bradley, R., Bunn, D., Clarke, C. and Wilson, T., 2008. Evaluating the power investment options with uncertainty in climate policy. Energy Economics, 30(4), pp.1933-1950.

Yu, W., Sheblé, G.B., Lopes, J.A.P. and Matos, M.A., 2006. Valuation of switchable tariff for wind energy. Electric Power Systems Research, 76(5), pp.382-388. 
Table 1: Assumptions for the valuation model.

\begin{tabular}{lc}
\hline \hline Investment cost & US\$ 227,960,561.11 \\
Fixed cost (O\&M) & US\$ 3,941,184.88 \\
Book-life (years) & $20-30$ \\
Depreciation Schedule & 5 years \\
Insurance cost (\% investment & $0.30 \%$ \\
cost) & US\$ 6,000 \\
Property tax (per MW) & $39.10 \%$ \\
Tax & $7.58 \%$ \\
Cost of debt & $55 / 45$ \\
Capital Structure (Debt-Equity) & $3.80 \%$ \\
Risk Free Rate & $6.62 \%$ \\
Market Risk Premium & $1.14 \%$ \\
Size Premium & $16 \%$ \\
Cost of equity & P
\end{tabular}

Source: U.S. Environmental Protection Agency (EPA, 2013). 
Table 2: Free cash flow for the first scenario.

Total revenues $(\mathbf{A}+\mathbf{B}+\mathbf{C})$

(A) Electricity sales at wholesales market

(B) REC sales

(C) Capacity sales to the grid

(-) Operational costs

(-) Insurance

(=)EBITDA

(-) Interest, depreciation and amortization

$(=)$ EBT

(-) Income tax

(+) Depreciation

(=) Free cash flow 
Table 3: Assumptions for the corn farm.

\begin{tabular}{lr}
\hline Total area (acre) & 17067 \\
Area of wind energy generator installation & 50 \\
Area to the corn plantation & 17017 \\
Land cost (Per Acre) & $\mathrm{US} \$ 4,600$ \\
Yield (bushels per planted acre) & 166 \\
Operation cost & $\mathrm{US} \$ 6,076,481.50$ \\
Property cost & $\mathrm{US} \$ 2,040,468.50$ \\
Avoided electricity (MW/acre) & 0.639 \\
Avoided rent of land & $\mathrm{US} \$ 600,000.00$ \\
Government payment (per year) & $\mathrm{US} \$ 49,408.00$ \\
Tax & $39.10 \%$ \\
Cost of debt & $4.00 \%$ \\
Capital Structure (Debt-Equity) & $13 / 87$ \\
Risk Free Rate & $3.80 \%$ \\
Market Risk Premium & $6.62 \%$ \\
Cost of equity & $8.3 \%$ \\
\hline \hline
\end{tabular}

Sources: Hau, 2013; USDA 2010, 2014a and 2014b; Foreman, 2014. 
Table 4: Free cash flow for the second scenario.

Total revenues $(\mathbf{A}+\mathbf{B}+\mathbf{C}+\mathbf{D}+\mathbf{E}+\mathbf{F})$

(A) Electricity sales at wholesales market

(B) REC sales

(C) Capacity sales to the grid

(D) Corm grain sales

(E) Avoided land rent

(F) Avoid electricity consumption

(-) Operational costs from wind farm

(-) Insurance from wind farm

(-) Operational cost from the corn farm

(-) Property cost

(=) EBITDA

(-) Interest, depreciation and amortization

(=) EBT

(-) Income tax

(+) Depreciation

(=) Free cash flow 
Table 5: MRM model parameters.

\begin{tabular}{lccc}
\hline \hline Parameters & $\eta$ & $\bar{S}$ & $\sigma$ \\
\hline Value & 619.96 & 35.16 & 9.65 \\
\hline \hline
\end{tabular}

Notes: $\eta$ is the mean reversion speed; $\bar{S}$ is the long-term equilibrium level of the stochastic variable; and $\sigma$ is the process volatility. 
Table 6: Jump diffusion parameters per season.

\begin{tabular}{lcccc}
\hline \hline & $\phi$ & $\bar{k}$ & $\gamma$ & $\phi \Delta t$ \\
\hline Summer & 79 & 11.83 & 43.07 & 0.009 \\
Fall & 13 & 81.31 & 7.67 & 0.001 \\
Winter & 4 & 81.76 & 2.88 & 0.000 \\
Spring & 19 & 86.76 & 14.11 & 0.002 \\
\hline \hline
\end{tabular}

Notes: $\phi$ is jump frequency; $\bar{k}$ is mean jump size; $\gamma$ is the standard deviation of the jump; and $\phi \Delta t$ is the probability of jump occurrence. 
Table 7: Model parameters.

\begin{tabular}{lccc}
\hline \hline Parameters & $\eta$ & $\bar{S}$ & $\sigma$ \\
\hline Value & 3.44 & 6.48 & 0.14 \\
\hline \hline
\end{tabular}

Notes: $\eta$ is the mean reversion speed; $\bar{S}$ is the long-term equilibrium level of the stochastic variable; and $\sigma$ is the process volatility. 
Table 8: Descriptive statistics for electricity and corn prices.

\begin{tabular}{|c|c|c|c|c|c|c|c|c|c|c|}
\hline & \multicolumn{2}{|c|}{ Summer } & \multicolumn{2}{|c|}{ Fall } & \multicolumn{2}{|c|}{ Winter } & \multicolumn{2}{|c|}{ Spring } & \multicolumn{2}{|c|}{ Corn price } \\
\hline & Real & Simulated & Real & Simulated & Real & Simulated & Real & Simulated & Real & Simulated \\
\hline Minimum & 4.9 & 14.06 & 15.01 & 10.73 & 19.63 & 9.83 & 19.04 & 12.22 & 5.48 & 5.52 \\
\hline Maximum & 238.78 & 238.32 & 94.16 & 101.58 & 85.09 & 91.84 & 125.88 & 109.93 & 9.09 & 7.36 \\
\hline Mean & 34.54 & 35.79 & 34.61 & 34.1 & 32.73 & 33.01 & 38.17 & 34.79 & 6.5 & 6.43 \\
\hline Standard Deviation & 20.35 & 12.22 & 8.82 & 9.45 & 6.3 & 9.51 & 9.64 & 10.53 & 0.36 & 0.24 \\
\hline Skewness & 4.42 & 3.13 & 1.58 & 0.81 & 2.13 & 0.7 & 1.88 & 1.06 & 1.57 & 0 \\
\hline Kurtosis & 29.51 & 27.56 & 5.58 & 4.23 & 9.85 & 3.77 & 8.24 & 5.02 & 6.96 & 3 \\
\hline Mode & 28.35 & 31.29 & 34.63 & 30.62 & 31.33 & 29.07 & 31.09 & 30.2 & 6.34 & 6.42 \\
\hline $25 \%$ Percentile & 24.29 & 28.32 & 29.11 & 27.36 & 28.87 & 26.15 & 31.33 & 27.27 & 6.28 & 6.27 \\
\hline $50 \%$ Percentile & 30.3 & 33.45 & 33.45 & 32.93 & 31.72 & 31.92 & 36.78 & 33.13 & 6.45 & 6.43 \\
\hline $75 \%$ Percentile & 38.14 & 40.18 & 38.85 & 39.56 & 35.39 & 38.68 & 43.06 & 40.46 & 6.67 & 6.59 \\
\hline
\end{tabular}




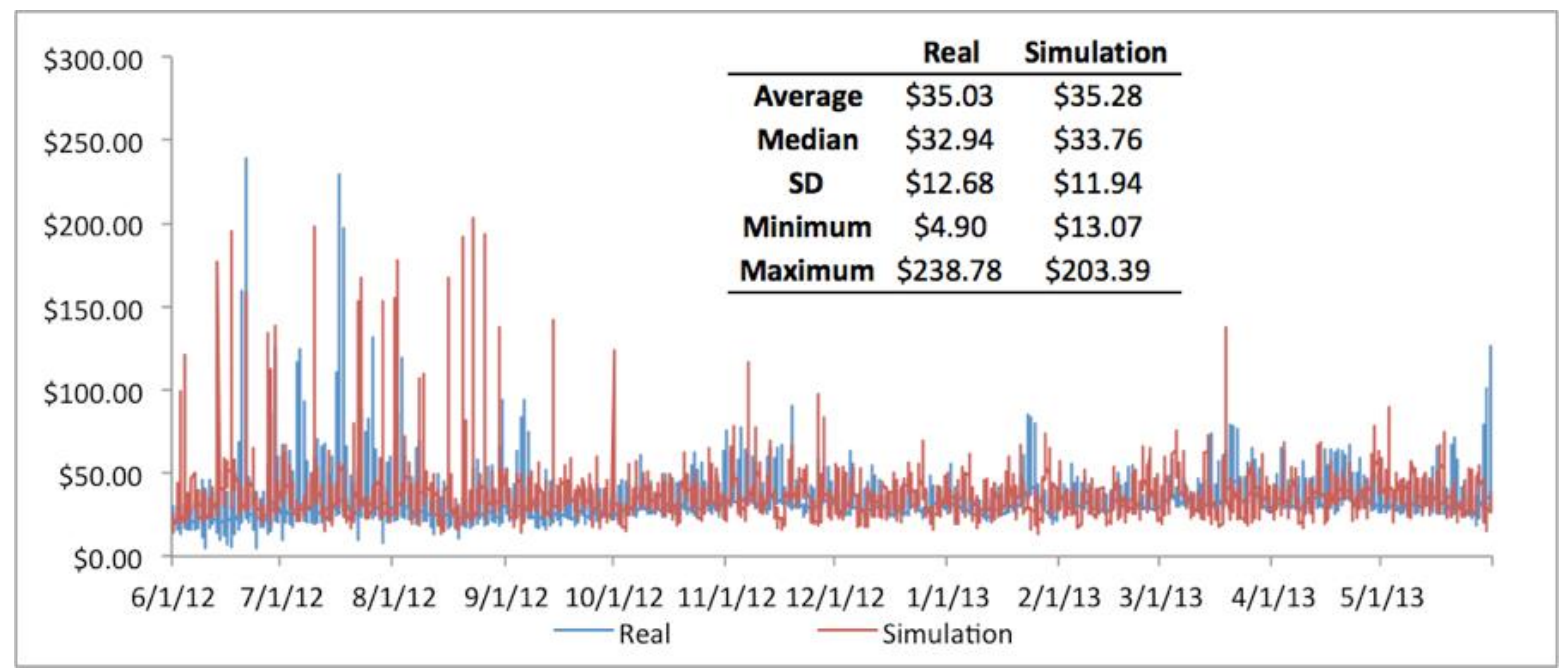

Figure 1: Comparison between the simulated and the historical series of electricity price of the hourly LMP day-ahead from ATSI_PJM from 06/01/2012 to 05/31/2013. Source: PJM, 2014 


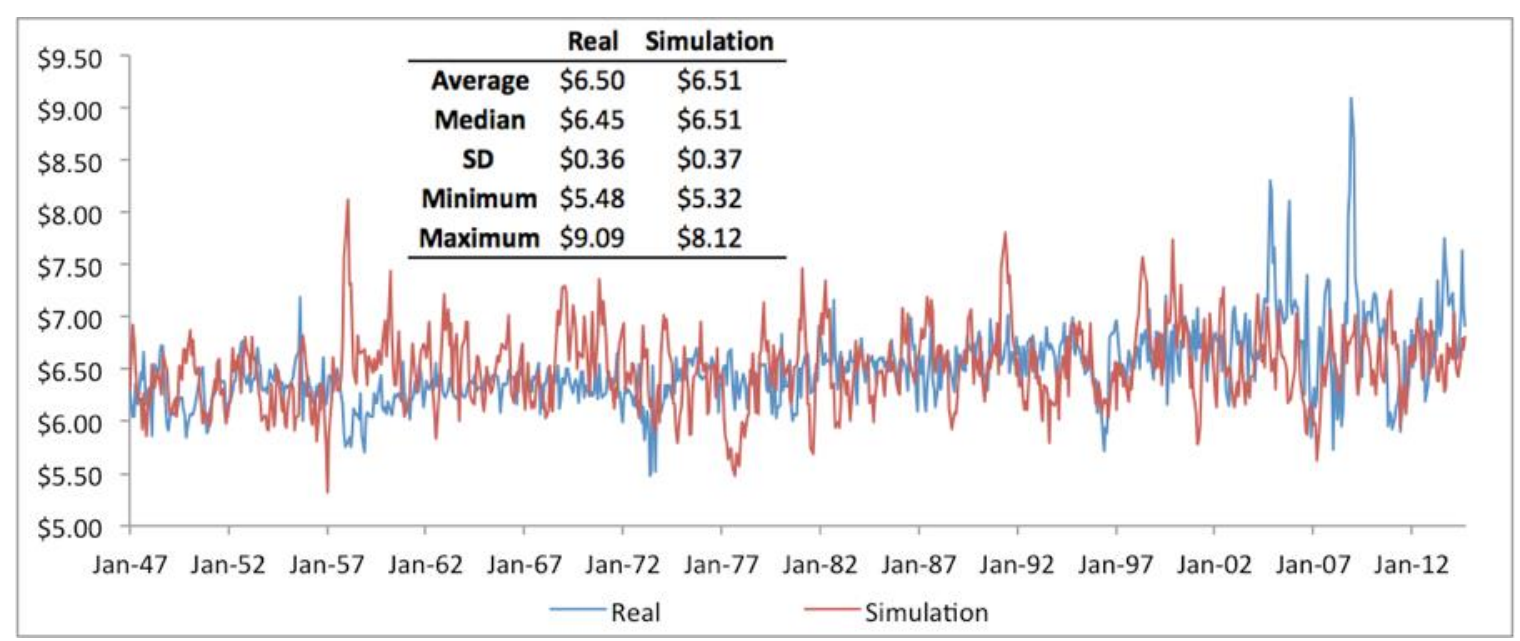

Figure 2: Comparison between simulated and historical series of monthly corn grain price received by farmers from Jan-1947 to May-13. Source: USDA, 2014. 


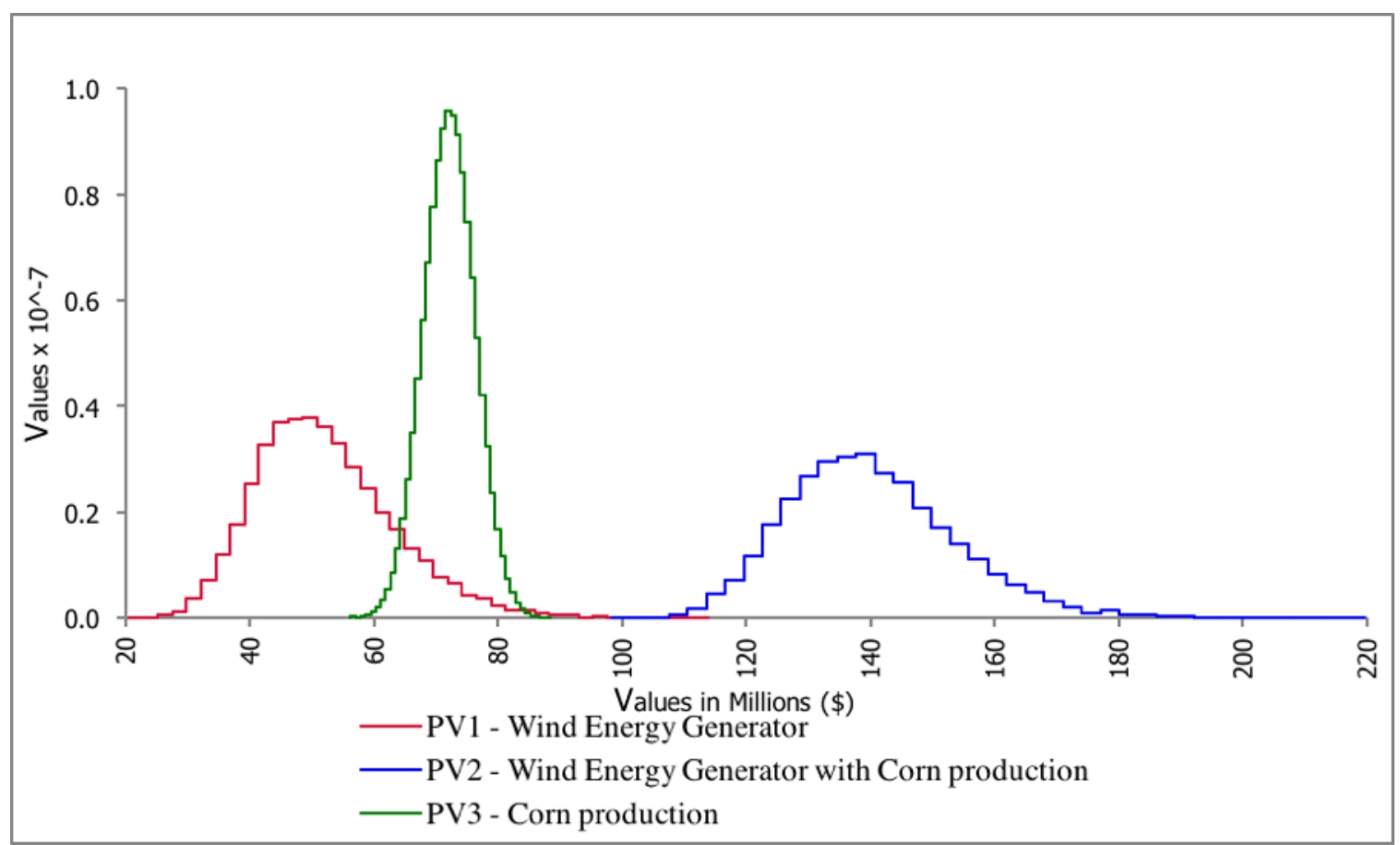

Figure 3: Histograms for simulated Present Values (PV) under different scenarios: $P V_{1}-$ wind power producer rents the land and commercializes electricity; $P V_{2}-$ wind power producer buys the land and commercializes both electricity and corn; $P V_{3}-$ agricultural farmer commercializes corn only. 


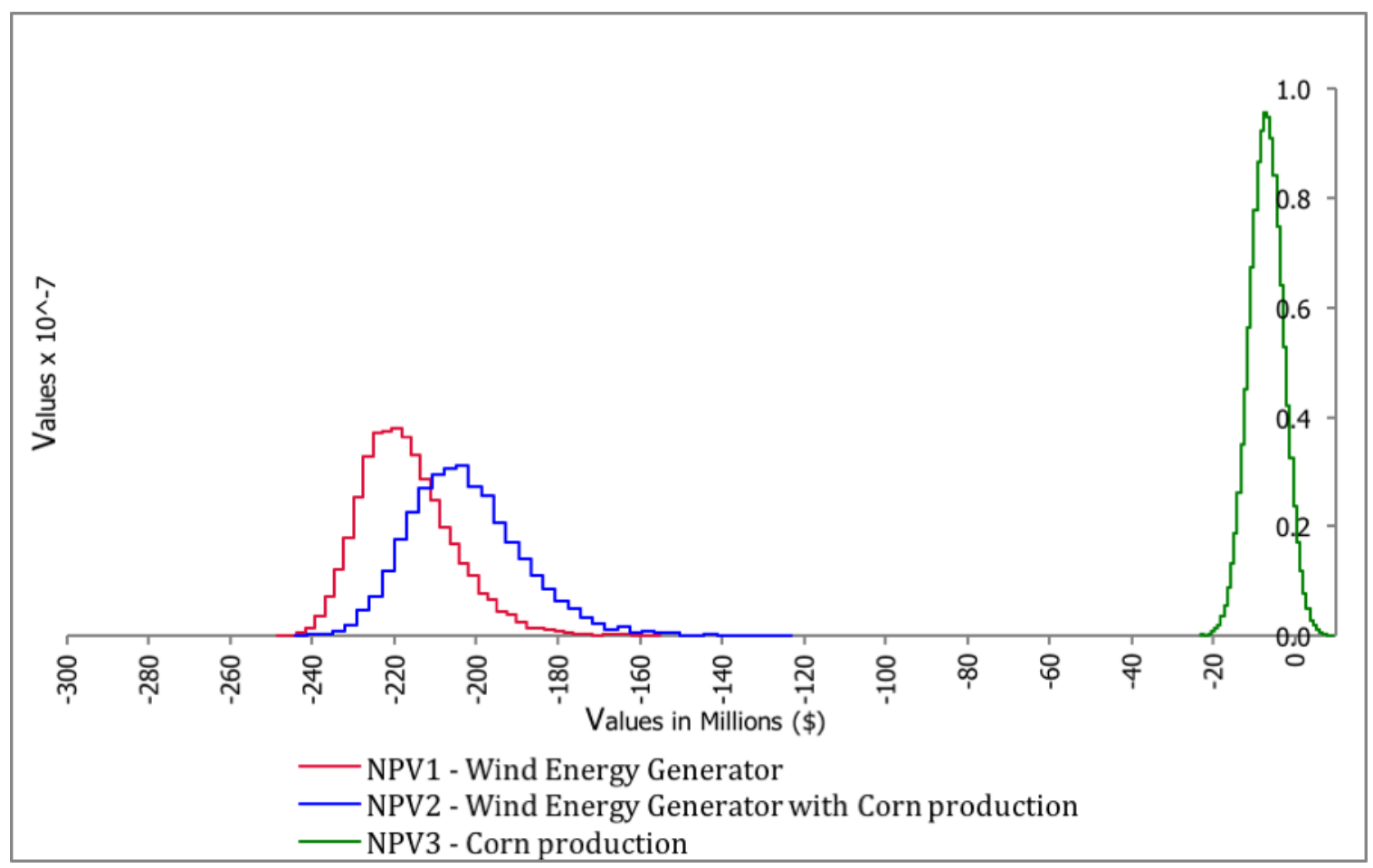

Figure 4: Histograms for simulated Net Present Values (NPV), CAPEX included, under different scenarios: $N P V_{1}$ - wind power producer rents the land and commercializes electricity; $N P V_{2}$ - wind power producer buys the land and commercializes both electricity and corn; $N P V_{3}$ - agricultural farmer commercializes corn only. 


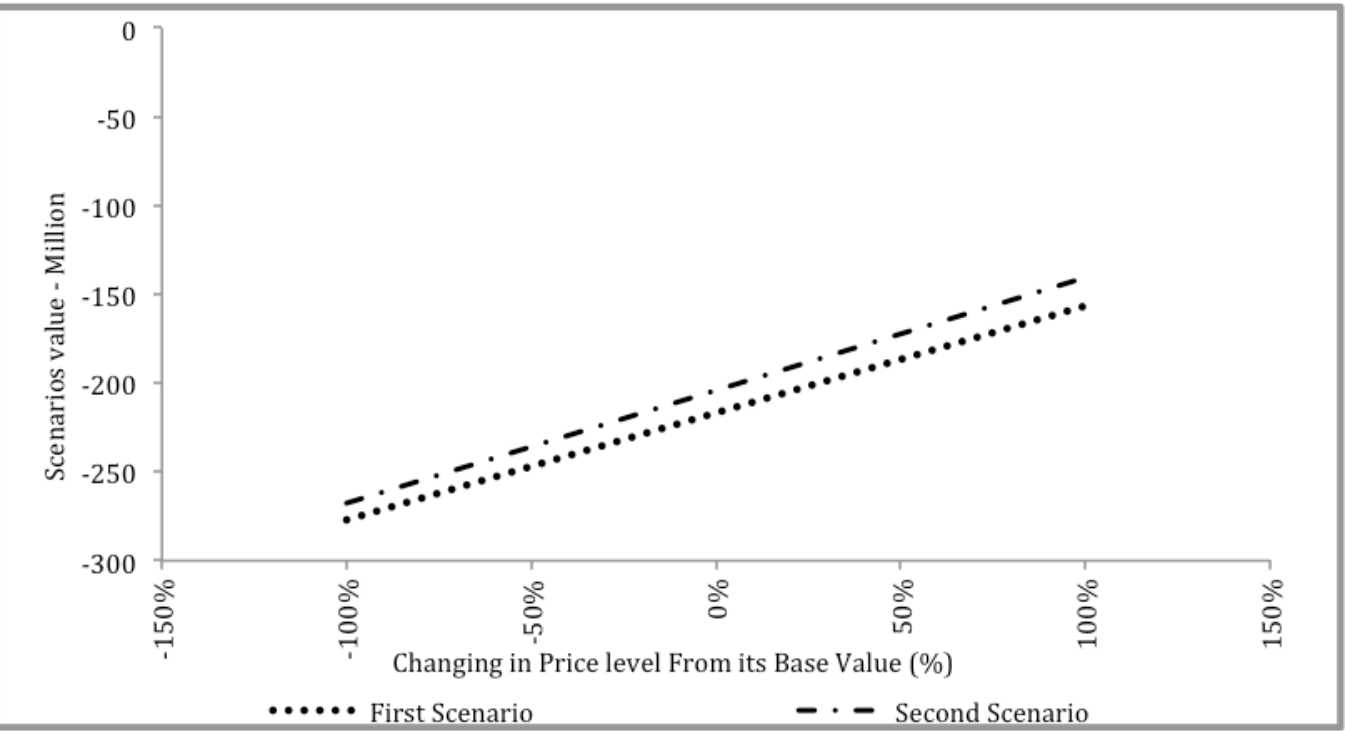

Figure 5: Sensitivity of the NPV (in US\$ millions) to different electricity prices under different scenarios: First scenario - wind power producer rents the land and commercializes electricity; second scenario - wind power producer buys the land and commercializes both electricity and corn. 


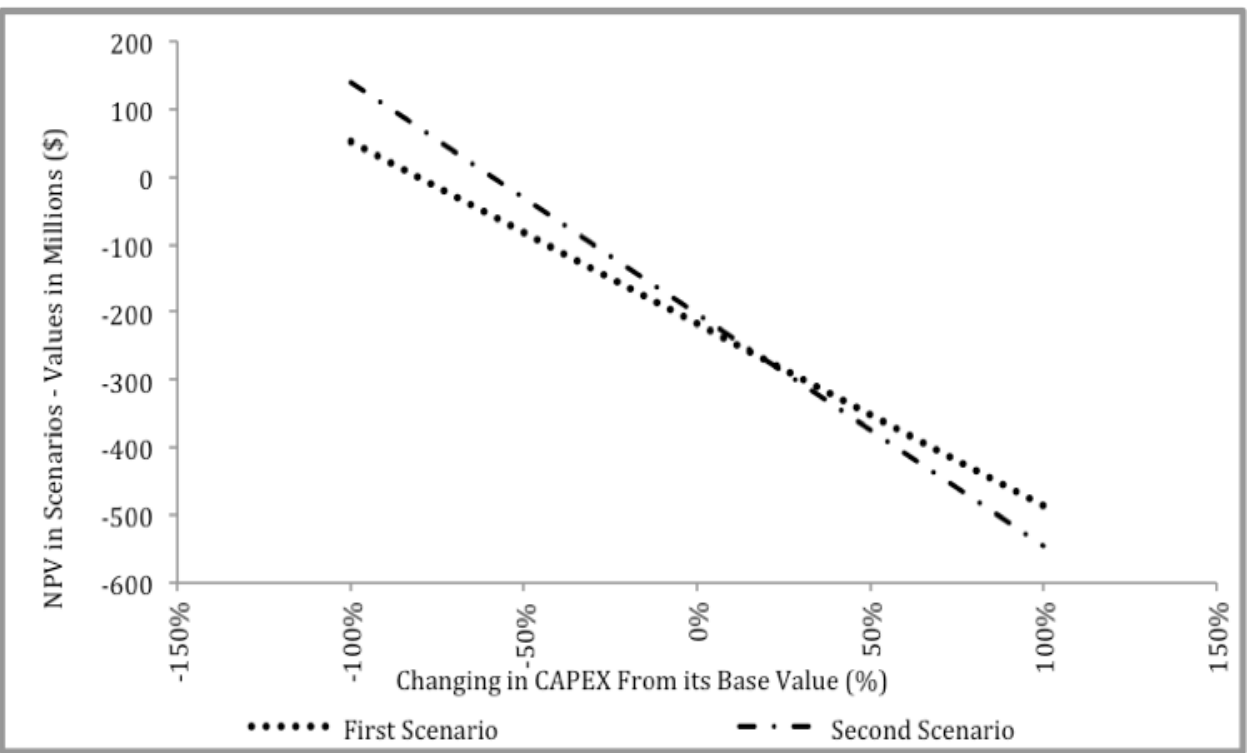

Figure 6: Sensitivity of the NPV (in US\$ millions) to different CAPEX levels under different scenarios: First scenario - wind power producer rents the land and commercializes electricity; second scenario - wind power producer buys the land and commercializes both electricity and corn. 